Article

\title{
Estimation of Fuel Economy Improvement in Gasoline Vehicle Using Cylinder Deactivation
}

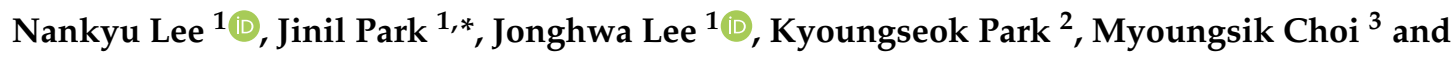 \\ Wongyu Kim ${ }^{3}$ \\ 1 Department of Mechanical Engineering, Ajou University, Suwon 16499, Gyeonggi, Korea; \\ lnk85@ajou.ac.kr (N.L.); jlee@ajou.ac.kr (J.L.) \\ 2 Department of Mechanical System Engineering, Kumho National Institute of Technology, \\ Gumi 39177, Gyeongbuk, Korea; kspark@kumoh.ac.kr \\ 3 Hyundai Motor Company, 150, Hyundaiyeonguso-ro, Jangdeok-ri, Namyang-eup, \\ Hwaseong-si 18280, Gyeonggi-do, Korea; ms_choi@hyundai.com (M.C.); whiteone@hyundai.com (W.K.) \\ * Correspondence: jpark@ajou.ac.kr; Tel.: +82-31-219-2337
}

Received: 8 October 2018; Accepted: 6 November 2018; Published: 8 November 2018

check for updates

\begin{abstract}
Cylinder deactivation is a fuel economy improvement technology that has attracted particular attention recently. The currently produced cylinder deactivation engines utilize fixed-type cylinder deactivation in which only a fixed number of cylinders are deactivated. As fixed-type cylinder deactivation has some shortcomings, variable-type cylinder deactivation with no limit on the number of deactivated cylinders is under research. For variable-type cylinder deactivation, control is more complicated and production cost is higher than fixed-type cylinder deactivation. Therefore, it is necessary to select the cylinder deactivation control method considering both advantages and disadvantages of the two control methods. In this study, a fuel economy prediction simulation model was created using the measurement data of various vehicles with engine displacements of 1.0-5.0 L. The fuel economy improvement of fixed-type cylinder deactivation was compared with that of variable-type cylinder deactivation using the created simulation. As a result of examining the fuel economy improvement of the test vehicle in the FTP-75 driving cycle, the improvement was $2.2-10.0 \%$ for fixed-type cylinder deactivation and $2.2-12.8 \%$ for variable-type cylinder deactivation. Furthermore, the effect of the engine load on fuel economy improvement under cylinder deactivation and the effect of changes in engine control were examined via a simulation.
\end{abstract}

Keywords: cylinder deactivation; vehicle modeling; pumping loss; vehicle fuel economy

\section{Introduction}

Fuel economy improvement technologies have been studied actively and applied to vehicles to address problems such as fossil fuel depletion and greenhouse gas regulations [1-5]. Among such technologies, cylinder deactivation has attracted particular attention recently. Cylinder deactivation reduces the pumping loss to increasing load of working cylinders by deactivating some cylinders in the engine under medium load [6-8]. Various studies have been conducted on cylinder deactivation technology. More of them were focused on the cylinder deactivation mechanism [9-11], the noise, vibration, and harshness due to cylinder deactivation operation [12,13], misfire detection [14], or air fuel ratio control logic [15]. The fuel economy improvement of cylinder deactivation presented by previous studies was between $6 \%$ and $22 \%$, and it significantly varied depending on the characteristics and control of the applied vehicle [16-20]. In particular, the fuel economy improvement was much different depending on the cylinder deactivation control method. Depending on the vehicle, the fuel economy improvement differed by more than $10 \%$ point [21]. 
The cylinder deactivation control method can be largely divided into the fixed type and variable type. The fixed-type cylinder deactivation deactivates only a fixed number of cylinders while the variable-type cylinder deactivation has no limit on the number of deactivated cylinders. For example, 6-cylinder fixed-type cylinder deactivation deactivates only three cylinders [22] and 8-cylinder fixed-type cylinder deactivation deactivates only four cylinders [23,24]. However, 8-cylinder variable-type cylinder deactivation can deactivate 1-7 cylinders depending on the operating conditions to maximize the fuel economy improvement [25]. While variable-type cylinder deactivation technology has a larger fuel economy improvement than the fixed-type method, its control logic is more complicated and the production cost is higher due to the increase in the operating unit. Although studies on the variable-type control method argue that the additional fuel economy improvement of more than $10 \%$ point is possible compared to the fixed type, a direct comparison is difficult because the fuel economy improvement value due to the control method is different as each researcher uses different vehicles and control logic.

As such, this study aims to quantify the fuel economy improvement by control method under the same conditions. In particular, the focus was given to the fuel economy difference between the fixed-type control and variable-type control. For this, a fuel economy prediction simulation environment was created based on the actual vehicle data. Although fuel economy prediction simulation on cylinder deactivation was performed in previous studies $[16,18,26]$, the control method was limited to the fixed type and studies on predicting fuel economy for the variable-type control are not available. Moreover, as modeling was performed using the engine efficiency data acquired through a static test, the results were somewhat different from the engine efficiency obtained from vehicles and it took a long time to acquire data for simulation.

Other than the fuel economy depending on the control method, various influence factors affecting cylinder deactivation were derived and their influences were identified.

\section{Modeling of Fuel Economy Prediction Simulation under Cylinder Deactivation}

In this study, accumulated driving cycle test data for vehicles with various specifications were used to identify the effect of cylinder deactivation. The primary physical modeling for vehicle performance was performed based on cycle unit cylinder pressure measurement data, and the modeling error was verified using driving cycle test results.

\subsection{Test Vehicle Selection and Driving Cycle Test Data Analysis}

The test vehicle was selected as a gasoline vehicle which have engine with $3,4,6$, or 8 cylinders. The engine displacement was determined to be 1.0-5.0 L depending on the number of cylinders. Their specifications are shown in Table 1. Data were acquired by conducting the FTP- 75 driving cycle test using the test vehicles. Data for simulation were summarized by analyzing the data acquired from the vehicle test.

Table 1. Specifications of test vehicles.

\begin{tabular}{ccccc}
\hline Specification & Vehicle $\mathbf{1}$ & Vehicle 2 & Vehicle 3 & Vehicle 4 \\
\hline Volume (L) & 1.0 & 2.4 & 3.3 & 5.0 \\
ETW (lb) & 2250 & 4000 & 4750 & 5000 \\
Number of cylinders & 3 & 4 & 6 & 8 \\
\hline
\end{tabular}

The data for modeling was created such that the data between related variables were expressed in graphs by dividing the FTP-75 driving cycle test data into phases, and modes selected for each interval were connected using an interval linear fitting line.

Figure $1 \mathrm{a}$ shows the indicated mean effective pressure (IMEP) and thermal efficiency measured from vehicle testing. The thermal efficiency increased as IMEP increased at low loads. The thermal 
efficiency remained at a certain level at intermediate loads but decreased as the load was increased further. These are typical load-dependent efficiency characteristics observed from gasoline engines.

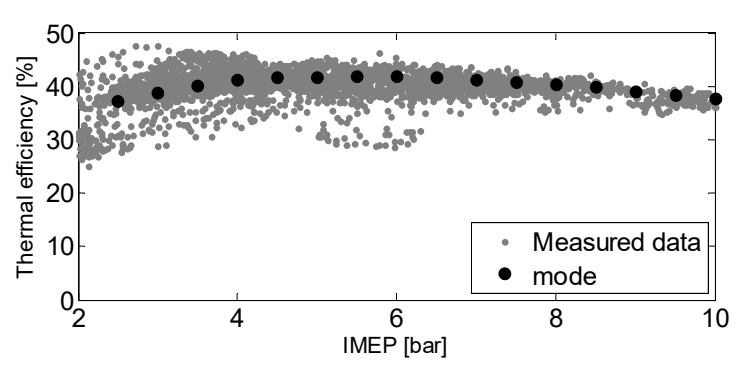

(a)

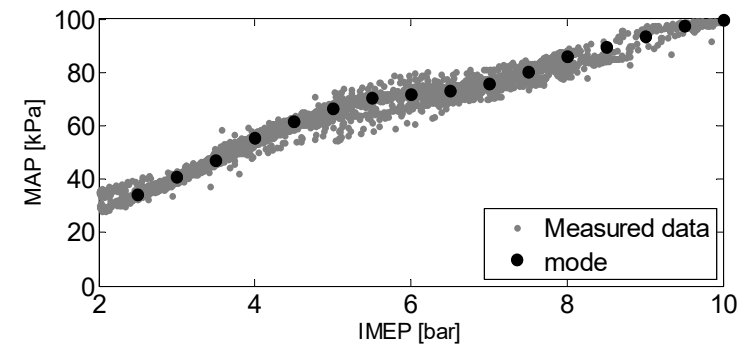

(b)

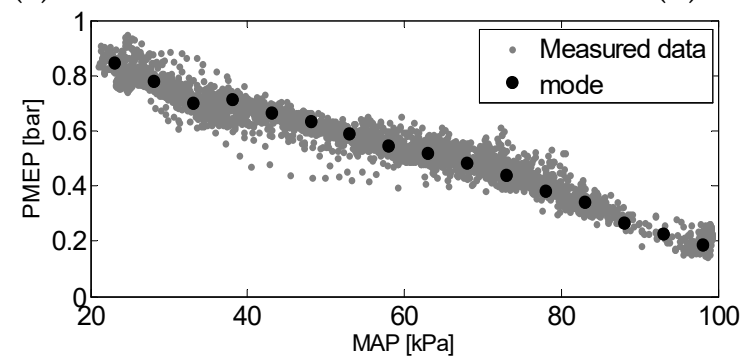

(c)

Figure 1. Test data analysis in phase 3 of FTP-75; (a) Modes of thermal efficiency divided by intervals; (b) Modes of manifold absolute pressure (MAP) divided by intervals; (c) Modes of pumping mean effective pressure (PMEP) divided by intervals.

Figure $1 \mathrm{~b}$ shows the relationship between IMEP and manifold absolute pressure (MAP). Although linear characteristics are generally expected between these two variables, a slight nonlinearity is observed owing to the thermal efficiency and intake air temperature.

Figure 1c shows the MAP and pumping mean effective pressure (PMEP). MAP and pumping loss show almost linear characteristics, as expected.

When the data above are applied to each test vehicle, similar overall patterns are observed. This implies that similar fuel economy improvements can be obtained when cylinder deactivation is applied under the same conditions.

\subsection{Development of Fuel Economy Prediction Simulation}

The following two assumptions were used for the cylinder deactivation simulation in this study.

The first assumption is that the base engine control is applied regardless of cylinder deactivation operation if the air amount per cylinder is the same. In other words, although the optimal values may be different during cylinder deactivation operation, it is inevitable to assume that the differences are not significant because such values cannot be confirmed in the engines.

The second assumption is that the same vehicle speed and load are used in the simulation. This implies that the same braking torque and engine speed are applied. Under these assumptions, the net indicated mean effective pressure (NMEP) must be the same before and after cylinder deactivation operation because other loads are not required except for the pumping loss in the vehicle to be changed owing to cylinder deactivation when cylinder deactivation is applied.

It is noteworthy that if only the PMEP can be reduced by cylinder deactivation operation, it is possible to decrease the IMEP by the same amount as the reduced PMEP, and the reduction in fuel corresponding to this decrease can improve the fuel economy. This is the basic concept used for simulating fuel economy. 
Simulation was performed by cycle, and the control logic was created to determine the number of deactivated cylinders for which NMEP was the same as the measured value and the fuel consumption was the lowest. For the stability of cylinder deactivation operation, the operating conditions were set to operate at an engine speed of $1000 \mathrm{rpm}$ or more and a vehicle speed of $20 \mathrm{~km} / \mathrm{h}$ or more.

Simulation was performed in the following process. Figure 2 shows the calculation process of the simulation in a flowchart.

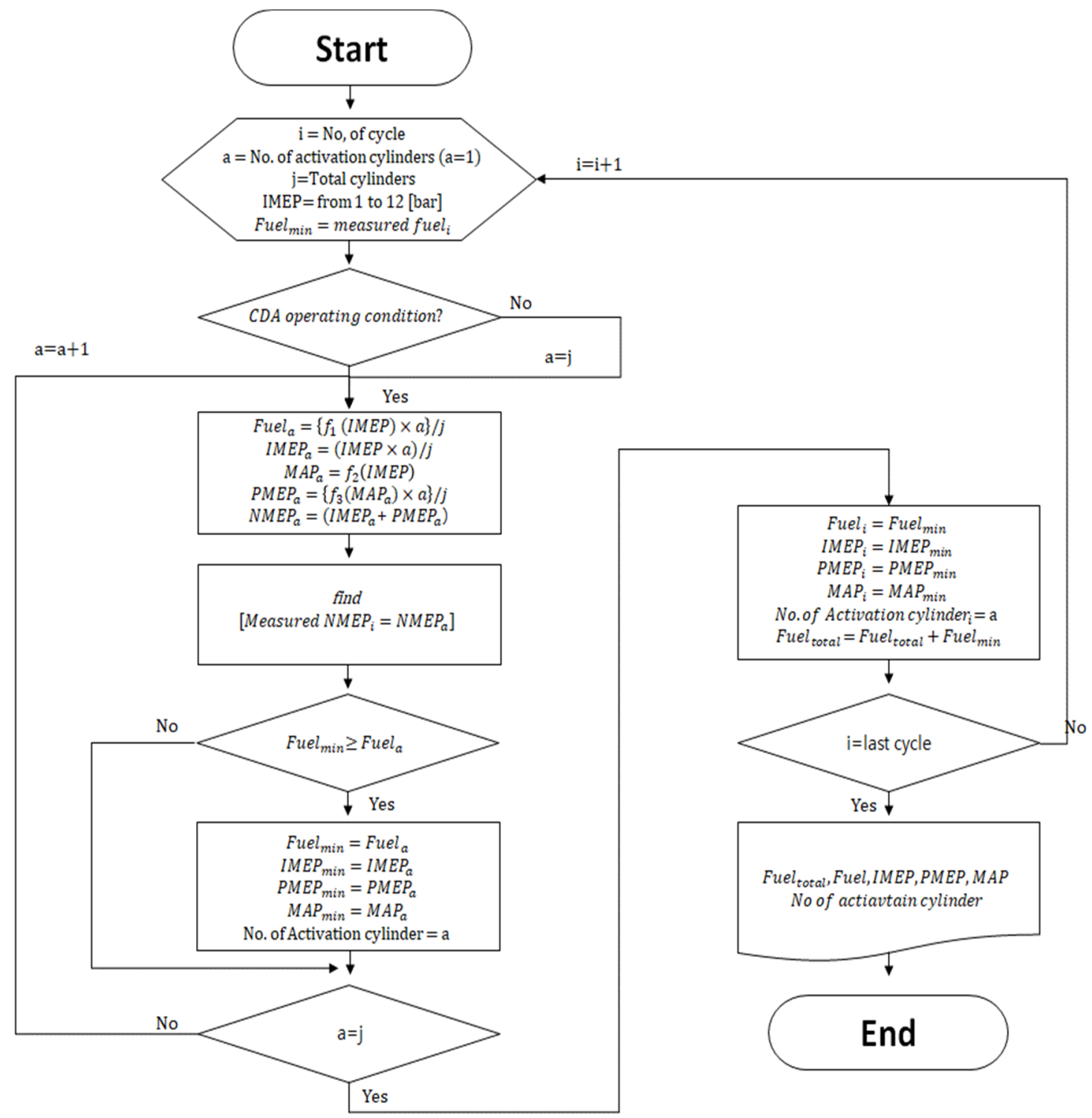

Figure 2. Flowchart of simulation.

1. Through the given vehicle data, initial conditions (the number of activated cylinders, fuel, etc.) were set and it was determined whether these conditions are the operating conditions of cylinder deactivation.

2. Using the data of IMEP and thermal efficiency $\left(f_{1}\right)$, IMEP and MAP $\left(f_{2}\right)$, and MAP and PMEP $\left(f_{3}\right)$, the fuel, MAP, IMEP, PMEP, and NEMP calculate for the given IMEP of 1-12 bars. The fuel, IMEP, and PMEP are calculated again based on the total displacement because they are calculated based on the activated cylinders.

3. Combinations (including IMEP, PMEP, MAP, and fuel) in which the measured NMEP is identical to the calculated NMEP are chosen. 
4. In the case cylinder deactivation operation, steps $2-4$ are repeated as the number of activated cylinders was increased to the number of total cylinders to determine the number of deactivated cylinders with the lowest fuel consumption. Data, such as the fuel, IMEP, and PMEP, were stored. When cylinder deactivation is not in operation, the number of cylinders is determined the total cylinder. data such as fuel, IMEP, and PMEP of the total cylinders are stored.

5. After steps 1-4 are repeated by cycle, the fuel amounts by cycle are added and the total fuel amount is calculated when all driving cycles are completed.

\subsection{Verification of Fuel Economy Prediction Simulation}

The completed fuel economy prediction simulation was verified comparing the IMEP, PMEP, MAP, and fuel consumption (i.e., the outputted simulation results) with the measured data. The simulation verification of previous studies did not mention much about the precision of simulation. Papers that mentioned the precision revealed that errors within 5\% existed when compared with the measured engine data in the static state [26].

Table 2 shows the verification data that summarize the measured and calculated results of a vehicle 3 using the mean values of the entire driving cycle, and Figure 3 shows the comparisons of the fuel masses in phase 3.

Table 2. Comparison between measured and calculated data of vehicle 3 in FTP-75.

\begin{tabular}{cccccc}
\hline Data & $\begin{array}{c}\text { Mean } \\
\text { IMEP [bar] }\end{array}$ & $\begin{array}{c}\text { Mean } \\
\text { PMEP [bar] }\end{array}$ & $\begin{array}{c}\text { Mean NMEP } \\
{[\text { bar] }}\end{array}$ & $\begin{array}{c}\text { Mean MAP } \\
{[\mathbf{k P a}]}\end{array}$ & $\begin{array}{c}\text { Accumulated Fuel } \\
\text { Mass Error [\%] }\end{array}$ \\
\hline Measured & 3.9 & 0.6 & 3.3 & 50.8 & less than $1 \%$ \\
Calculated & 3.9 & 0.6 & 3.3 & 51.6 & \\
\hline
\end{tabular}

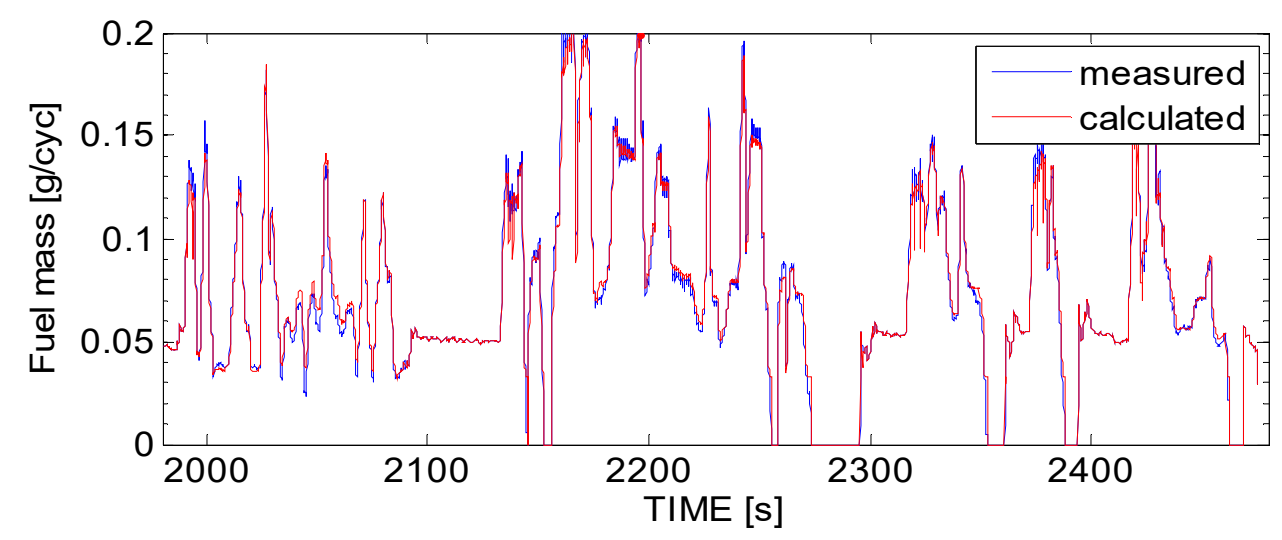

Figure 3. Comparison between measured and calculated fuel rate of vehicle 3 in phase 3 of FTP-75.

Table 2 shows that the measured NMEP is the same as the calculated NMEP ( 3.3 bar) and that the mean PMEP, MAP, and fuel consumption have almost no error.

Figure 3 shows the comparisons of the fuel masses by cycle and reveals that the measured and calculated values are similar, being 412 and $411 \mathrm{~g}$, respectively, with less than $1 \%$ error.

\section{Fuel Economy Improvement under Cylinder Deactivation}

When the completed fuel economy prediction model was applied to fixed-type and variable-type cylinder deactivation for each vehicle, the fuel economy improvement was examined and we confirmed the cause of difference in fuel economy improvement between two cylinder deactivation control methods. Furthermore, the effects of variables that may occur when the engine load and engine thermal efficiency were changed under cylinder deactivation application were investigated. 


\subsection{Comparision of Fuel Economy Improvement by Cylinder Deactivation Method}

In this study, fixed-type and variable-type cylinder deactivation fuel economy simulations were performed for the test vehicles, and the fuel economy improvement depending on the cylinder deactivation method were compared using the obtained IMEP, PMEP, MAP, and fuel.

Table 3 summarizes the fuel economy improvement simulation results under cylinder deactivation application for each vehicle. The mean NMEP values are different because the engine displacement and equivalent test weight (ETW) are different. Furthermore, the fuel economy improvement ranges from $2.2 \%$ to $12.9 \%$; it was lowest for vehicle 1 and highest for vehicle 4 .

Table 3. Summary of fuel economy improvement under cylinder deactivation for each vehicle in FTP-75.

\begin{tabular}{cccccc}
\hline Specification & & Vehicle 1 & Vehicle 2 & Vehicle 3 & Vehicle 4 \\
\hline Volume (l) & & 1.0 & 2.4 & 3.3 & 5.0 \\
Mean NMEP (bar) & & 4.5 & 3.1 & 3.3 & 2.2 \\
Fuel economy improvement (\%) & Fixed & 2.2 & 6.3 & 5.2 & 10.0 \\
& Variable & 2.2 & 6.8 & 6.6 & 12.9 \\
\hline
\end{tabular}

A comparison of the fuel economy improvement between variable-type cylinder deactivation and fixed-type cylinder deactivation revealed that the fuel economy improvement was larger as the number of cylinders and displacement increased and the effect was smaller as the engine size decreased. The fuel economy improvement of variable-type cylinder deactivation increased for engines with larger displacement because the number of cylinders to be controlled increased.

Although the predicted fuel economy improvement was compared, as shown in Table 3, instantaneous simulation data were used to examine the fuel economy improvement under cylinder deactivation application in more detail. Instantaneous data were examined using the data for vehicle 3. Table 4 summarizes the mean engine performance data of the driving cycle. Figure 4 show the instantaneous data in phase 3.

Table 4. Summary of mean engine performance data under cylinder deactivation in FTP-75.

\begin{tabular}{ccccccc}
\hline & & $\begin{array}{c}\text { Mean IMEP } \\
\text { [bar] }\end{array}$ & $\begin{array}{c}\text { Mean PMEP } \\
\text { [bar] }\end{array}$ & $\begin{array}{c}\text { Mean } \\
\text { NMEP [bar] }\end{array}$ & $\begin{array}{c}\text { Mean MAP } \\
{[\mathbf{k P a}]}\end{array}$ & $\begin{array}{c}\text { Fuel Economy } \\
\text { Improvement [\%] }\end{array}$ \\
\hline $\begin{array}{c}\text { Base engine } \\
\text { Cylinder Deactivation }\end{array}$ & Fixed & 3.90 & 0.6 & 3.31 & 51.6 & - \\
Engine & Variable & 3.70 & 0.39 & 3.31 & 61.5 & 5.2 \\
\hline
\end{tabular}

In Table 4, the NMEP values are the same but the IMEP, PMEP, and MAP values are different. As the cylinder deactivation engine is a technology for decreasing the pumping loss by increasing the load of activated cylinders, it has higher mean MAP than the base engines and the fuel economy improvement occurs due to the decrease in the average PMEP.

As for the cylinder deactivation control methods, variable-type cylinder deactivation can control the number of cylinders more easily than fixed-type cylinder deactivation. Variable-type cylinder deactivation exhibited 1.4\% higher fuel economy improvement than fixed-type cylinder deactivation because the average MAP increased and the average PMEP decreased.

Figure 4a shows the instantaneous MAP values of the base engine and cylinder deactivation engine. The black line represents the base engine, the blue line the fixed-type cylinder deactivation engine, and the red line the variable-type cylinder deactivation engine. Both cylinder deactivation engines exhibited higher MAP than the base engine, and the parts without cylinder deactivation operation operated in the same way as the base engine. Under the operation of variable-type cylinder deactivation, the MAP increased to favorable $80-90 \mathrm{kPa}$ due to cylinder deactivation operation. In the case of fixed-type cylinder deactivation, however, the region with an excellent fuel economy 
improvement could be exceeded depending on the load because the number of deactivated cylinders was limited.

Figure $4 \mathrm{~b}$ shows comparisons of the PMEP values. Under cylinder deactivation operation, the PMEP becomes lower compared to that of the base engine. For fixed-type cylinder deactivation, the pumping loss reduction decreased compared to variable-type cylinder deactivation due to the same reason as the MAP.

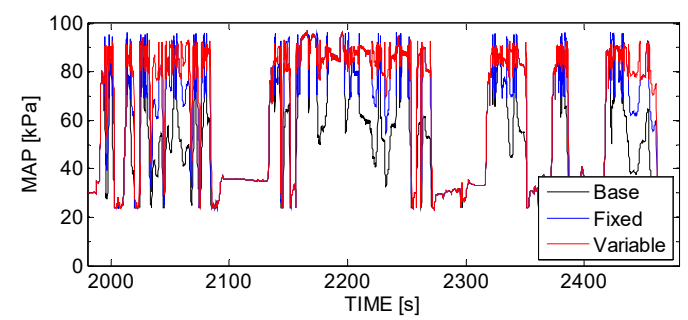

(a)

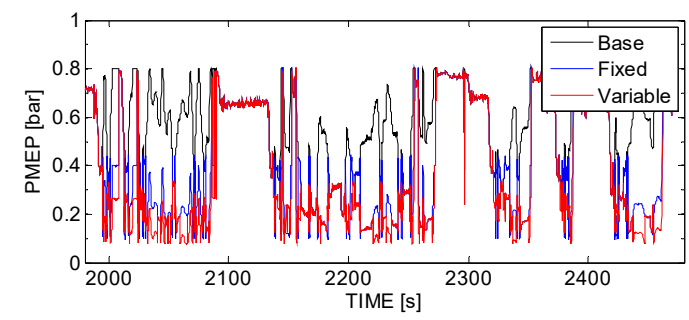

(b)

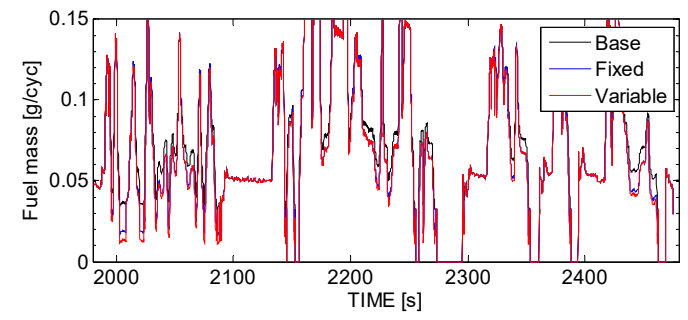

(c)

Figure 4. Comparison of results MAP between base engine and cylinder deactivation engine in phase 3 of FTP-75; (a) MAP; (b) PMEP; (c) fuel mass.

Figure 4c shows the comparisons of the instantaneous fuel masses. The fuel mass decreased significantly in the low-load region where the PMEP was reduced significantly in Figure 4b; however, it decreased only slightly in the high-load region where the PMEP difference was small. For fixed-type cylinder deactivation, the instantaneous fuel amount was high compared to variable-type cylinder deactivation because of many areas with high PMEP.

In previous papers, the fuel economy improvement of cylinder deactivation presented by previous studies was between $6 \%$ and $22 \%$, and the fuel economy improvement by cylinder deactivation control method differed by more than $10 \%$. However, it significantly varied depending on the condition and control of the applied vehicle. This study confirmed the fuel economy improvement by cylinder deactivation under the same conditions and control. When the cylinder deactivation was applied to the test vehicle, it was confirmed that the fuel efficiency improvement of 2.2-12.9\%. Depending on the engine displacement, the fuel economy improvement was changed by up to $10.7 \%$. Depending on the cylinder deactivation control method, the fuel economy improvement was changed by up to $2.9 \%$.

The fuel economy improvement of cylinder deactivation varied depending on the engine as well as vehicle specifications. As the fuel economy improvements shown in Table 3 resulted from applying all the aforementioned variables, they differed depending on the vehicle.

Under cylinder deactivation application, the influence of the aforementioned variables must be examined because they may change the fuel economy improvement. Therefore, a simulation was performed to examine the influence of changes in engine load and thermal efficiency at high load on fuel economy improvement, which may occur owing to the use of the cylinder deactivation engine.

\subsection{Fuel Economy Improvement under Cylinder Deactivation According to Engine Load Change}

After this section, fuel economy prediction was performed only for variable-type cylinder deactivation, which exhibited a larger fuel economy improvement than fixed-type cylinder deactivation. The target vehicle was vehicle 3 . 
When a cylinder deactivation engine is used in a vehicle, the change in driving resistance is small because the vehicle exterior is the same but the vehicle weight changes with the engine replacement. If the vehicle weight changes, the engine load changes; thus, the fuel economy improvement also changes. Furthermore, the fuel economy improvement will change owing to engine load changes caused by other external factors.

A simulation was performed to examine the fuel economy improvement under $10 \%$ increase and $10 \%$ decrease in vehicle weight. In addition, the tendency of fuel economy improvement according to engine load changes was identified.

Table 5 shows comparisons of the engine mean NMEP values and fuel economy improvements according to vehicle weight change. As the vehicle weight increased, the engine load increased and the fuel economy improvement decreased.

Table 5. Summary of fuel economy improvement by weight change in FTP-75.

\begin{tabular}{|c|c|c|c|}
\hline & \multicolumn{3}{|c|}{ Vehicle Weight [ETW 4750] } \\
\hline & $10 \%$ Decrease & Base & $10 \%$ Increase \\
\hline Mean NMEP (bar) & 3.2 & 3.3 & 3.4 \\
\hline Fuel economy improvement [\%] & 7.0 & 6.6 & 6.3 \\
\hline
\end{tabular}

Table 6 shows the tendency of fuel economy improvement according to engine load change. As shown by the results in Table 5, the fuel economy improvement decreased as the engine load increased. Figure 5 explain these results.

Table 6. Summary of fuel economy improvement by mean NMEP in FTP-75.

\begin{tabular}{cccc}
\hline & Mean NMEP Decrease & Base & Mean NMEP Increase \\
\hline Mean NMEP (bar) & 2.8 & 3.3 & 3.8 \\
Fuel economy improvement [\%] & 9.1 & 6.6 & 4.6 \\
\hline
\end{tabular}

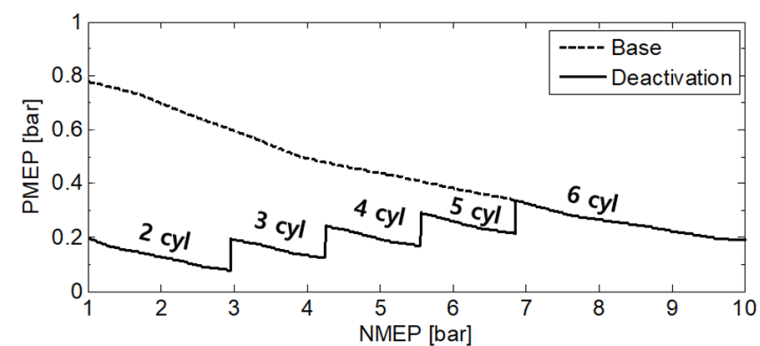

(a)

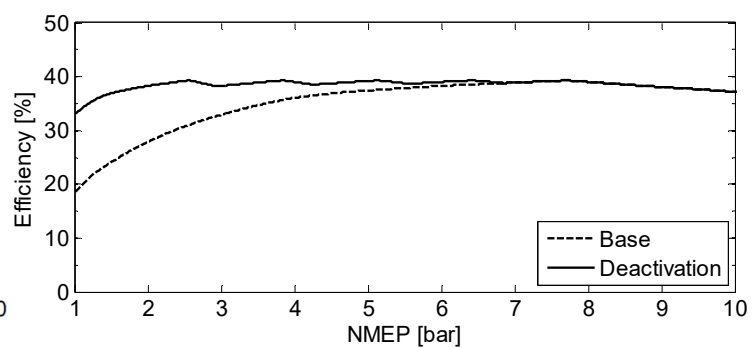

(b)

Figure 5. Comparison of results between base engine and cylinder deactivation engine; (a) PEMP; (b) engine efficiency.

Figure 5a shows the PMEP according to the NMEP. The dotted and solid lines represent the base engine and cylinder deactivation engine, respectively. In the low-load region, the difference in the PMEP was large because the number of deactivated cylinders was large. However, as the engine load increased, the number of deactivated cylinders decreased, resulting in no difference in the PMEP from the NMEP of $\sim 7$ bar. From 7 bar, the engine operated similarly as the base engine because the cylinder deactivation application afforded no advantage.

Figure $5 b$ shows the engine efficiency according to the NMEP. The difference between the solid line, which represents the efficiency of the cylinder deactivation engine, and the dotted line, which represents the efficiency of the base engine, is the fuel improvement that can be obtained owing to cylinder deactivation operation according to the load. The fuel improvement occurs owing to the 
aforementioned difference in the PMEP and in the thermal efficiency of the activated cylinders caused by cylinder deactivation operation; this can be confirmed from Figure 5 a.

Therefore, when the mean engine load increases, the reduction in pumping loss under cylinder deactivation operation decreases because the engine operates under higher loads than the base engine; thus, the fuel economy improvement is decreased.

3.3. Fuel Economy Improvement under Cylinder Deactivation According to Engine Thermal Efficiency Change at High Load

A simulation was performed to examine the fuel economy improvement under the assumption that all control is the same as that of the base engine under cylinder deactivation application. However, as each vehicle has a specific output, and drivability, its thermal efficiency may change at high load. Therefore, the effect of engine thermal efficiency on fuel economy improvement was examined through a simulation.

The thermal efficiency curves actually obtained from the data of various vehicles were used, and a total of three curves were chosen as shown in Figure 6. Case 1 is the thermal efficiency curve from phase 3 of vehicle 4, and Case 2 is the thermal efficiency curve from phase 3 of vehicle 3 . Case 3 present data obtained from the vehicle with the best thermal efficiency curve among the test vehicles. The cause of the difference between the thermal efficiency curves of Case 1 and Case 2 is not ignition retard due to the suppression of knock because the coolant temperature of both vehicles operates similarly. However, it is expected that the efficiency is reduced by the calibration for the ride comfort because vehicle 4 emphasizes the ride comfortable rather than the fuel consumption as compared with vehicle 3.

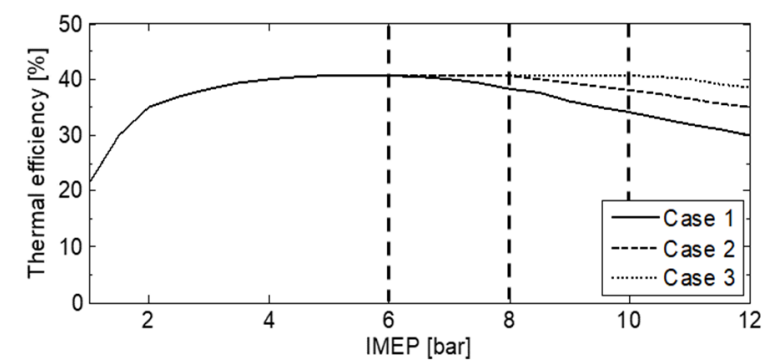

(a)

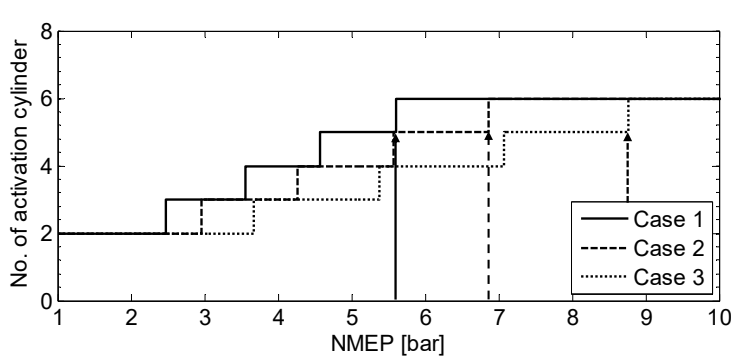

(b)

Figure 6. Comparison of data between cases; (a) thermal efficiency; (b) number of activated cylinders in cases 1, 2, and 3 and NMEP.

The IMEP value for the highest thermal efficiency was 6, 8, and 10 bar for cases 1, 2, and 3, respectively; this can be considered the maximum operating region of the activated cylinders under cylinder deactivation operation.

Figure $6 \mathrm{~b}$ shows the number of activated cylinders according to the NMEP under cylinder deactivation operation. The NMEP of the cylinder deactivation termination point increased in the order of Cases 3, 2, and 1. The IMEP values for the highest thermal efficiency show the same order, indicating that the cylinder deactivation region increases when the region with excellent engine thermal efficiency operates at high load.

Table 7 summarizes the fuel economy improvement in the three cases under cylinder deactivation operation. As the operating region of cylinder deactivation increases, the mean PMEP decreased and the mean MAP increased because the activated cylinders operated at high load. The fuel economy improvement was in the order of cases 3,2, and 1; the operating region of cylinder deactivation showed the same order.

The fuel economy improvement showed a difference of $0.6 \%$ from the value shown for vehicle 3 in Table 3. This is because the thermal efficiency curve obtained from each phase was applied when the fuel economy improvement in vehicle 3 was examined, although the thermal efficiency for each case 
was applied throughout the entire driving cycle intervals to examine the fuel economy improvement according to the difference in thermal efficiency.

Table 7. Fuel economy improvement in FTP-75 of each case.

\begin{tabular}{cccc}
\hline & Case 1 & Case 2 & Case 3 \\
\hline Mean MAP (kPa) & 62.7 & 66.5 & 70.1 \\
Mean PMEP (bar) & 0.37 & 0.33 & 0.30 \\
Fuel economy improvement $(\%)$ & 6.1 & 7.2 & 8.4 \\
\hline
\end{tabular}

In summary, Case 1 exhibited the lowest thermal efficiency while Case 3 exhibited the highest thermal efficiency from the thermal efficiency curves alone, indicating that the test vehicles had some differences in thermal efficiency. Such differences are caused by vehicle temperature control or vehicle drivability, and thus they may occur depending on the vehicle calibration. As the fuel economy improvement of $2.3 \%$ may occur depending on the thermal efficiency, calibration for using the high-load region with low pumping loss is required for the development of a cylinder deactivation vehicle. In addition, more precise vehicle thermal management and knock control are required for using the high-load region.

\section{Conclusions}

In this study, simulation capable of fixed-type and variable-type cylinder deactivation control was created using the measured vehicle data, and the results were verified through a comparison with the measured data. Using the completed simulation, the expected fuel economy improvement of fixed-type and variable-type cylinder deactivation were compared for each vehicle, and the influences of variables that may occur depending on the vehicle application and the causes were investigated.

1. The fuel economy improvement under cylinder deactivation was $2.2-12.9 \%$ depending on the vehicle. The fuel economy improvement differed depending on the engine displacement, engine load, and engine control.

2. The fuel economy improvement was $2.2-10.0 \%$ for fixed-type cylinder deactivation and $2.2-12.9 \%$ for variable-type cylinder deactivation. The difference in the fuel economy improvement between variable-type cylinder deactivation and fixed-type cylinder deactivation was large for vehicles with large displacement and many cylinders. This is because the control of variable-type cylinder deactivation is easier and the pumping loss reduction is larger when there are more cylinders.

3. When the engine load changed owing to the change in vehicle weight or driving resistance, the fuel economy improvement with cylinder deactivation changed from $6.6 \%$ to $4.6-9.1 \%$. Such differences occurred owing to engine pumping loss reduction caused by the change in the engine operating region.

4. When the engine thermal efficiency changed according to the displacement per cylinder or engine control characteristics, the fuel economy improvement with cylinder deactivation changed from $7.2 \%$ to $6.1-8.4 \%$. This is because the cylinder deactivation operating region differed depending on the thermal efficiency change.

Author Contributions: The contribution of the authors is summarized as follows: Conceptualization, K.P. and J.L.; software, N.L. and J.P.; data curation, M.C. and W.K.; writing-review and editing, N.L. and J.P.

Funding: This research received no external funding.

Conflicts of Interest: The authors declare no conflict of interest.

\section{References}

1. Peckham, R.; Basu, S.; Ribeiro, M.; Walker, S. Harmonizing and Rationalizing Lightweighting within Fuel Efficiency Regulations Across NA, EU and China. SAE Int. J. 2017, 10, 455-464. [CrossRef] 
2. Thomas, J. Vehicle Efficiency and Tractive Work: Rate of Change for the Past Decade and Accelerated Progress Required for U.S. Fuel Economy and $\mathrm{CO}_{2}$ Regulations. SAE Int. J. 2016, 9, 290-305. [CrossRef]

3. National Service Center for Environmental Publications. Regulatory Impact Analysis: Final Rulemaking for 2017-2025 Light-Duty Vehicle Greenhouse Gas Emission Standards and Corporate Average Fuel Economy Standards; EPA-420-R-12-016; National Service Center for Environmental Publications: Washington, DC, USA, 2012.

4. Turner, J.W.G.; Pearson, R.J.; Kenchington, S.A. Concepts for improved fuel economy from gasoline engines. Int. J. Eng. Res. 2005, 6, 137-157. [CrossRef]

5. Gis, W.; Bielaczyc, P. Emission of $\mathrm{CO}_{2}$ and Fuel Consumption for Automotive Vehicles. SAE Tech. Pap. 1999. [CrossRef]

6. Vendan, S.P.; Sathish, T.; Sathishkumar, S. Reduction of fuel consumption in multicylinder engine by cylinder deactivation technique. Eng. Ann. Fac. Eng. 2009, 15, 20.

7. Osman, A.K.; Hikmet, A.; Alper, T.C. Methods to improve efficiency of four stroke, spark ignition engines at part load. Energy Convers. Manag. 2005, 46, 3202-3220. [CrossRef]

8. Michael, k. Cylinder Deactivation Reborn-Part 1. 2005. Available online: http://www.autospeed.com/ $\mathrm{cms}$ /article.html? \&title=Cylinder-Deactivation-Reborn-Part-1\&A=2618 (accessed on 1 October 2018).

9. Flierl, R.; Lauer, F.; Breuer, M.; Hannibal, W. Cylinder Deactivation with Mechanically Fully Variable Valve Train. SAE Int. J. 2012, 5, 207-215. [CrossRef]

10. Kreuter, P.; Heuser, P.; Reinicke-Murmann, J.; Erz, R.; Stein, P.; Peter, U. Meta-CVD System an Electro-Mechanical Cylinder and Valve Deactivation System; SAE Technical Paper; SAE International: Warrendale, PA, USA, 2001. [CrossRef]

11. Mueller, R.; Uitvlugt, M. Valve Selector Hardware; SAE Technical Paper; SAE International: Warrendale, PA, USA, 1978. [CrossRef]

12. Serrano, J.; Routledge, G.; Lo, N.; Shost, M.; Srinivasan, V.; Ghosh, B. Methods of evaluating and mitigating $\mathrm{NVH}$ when operating an engine in dynamic skip fire. SAE Int. J. 2014, 7, 1489-1501. [CrossRef]

13. Thompson, S.; Brechko, A. Front End Accessory Drive Vibration Control Solutions for Engines with Cylinder Deactivation; SAE Technical Paper; SAE International: Warrendale, PA, USA, 2007. [CrossRef]

14. Chen, S.K.; Chien, L.; Nagashima, M.; Van Ess, J.V.; Hashemi, S. Misfire detection in a dynamic skip fire engine. SAE Int. J. 2015, 8, 389-398. [CrossRef]

15. Kwon, M.; Lee, M.; Kim, J.; Sunwoo, M. Transient air-fuel ratio control of the cylinder deactivation engine during mode transition. Trans. Korean Soc. Autom. Eng. 2011, 19, $26-34$.

16. Kuruppu, C.; Pesiridis, A.; Rajoo, S. Investigation of Cylinder Deactivation and Variable Valve Actuation on Gasoline Engine Performance; SAE Technical Paper; SAE International: Warrendale, PA, USA, 2014. [CrossRef]

17. Fujiwara, M.; Kumagai, K.; Segawa, M.; Sato, R.; Tamura, Y. Development of a 6-Cylinder Gasoline Engine with New Variable Cylinder Management Technology; SAE Technical Paper; SAE International: Warrendale, PA, USA, 2008. [CrossRef]

18. Leone, T.; Pozar, M. Fuel Economy Benefit of Cylinder Deactivation-Sensitivity to Vehicle Application and Operating Constraints; SAE Technical Paper; SAE International: Warrendale, PA, USA, 2001. [CrossRef]

19. Hatano, K.; Iida, K.; Higashi, H.; Murata, S. Development of a New Multi-Mode Variable Valve Timing Engine; SAE Technical Paper; SAE International: Warrendale, PA, USA, 1993. [CrossRef]

20. Fukui, T.; Nakagami, T.; Endo, H.; Katsumoto, T.; Danno, Y. Mitsubishi Orion-MD—A New Variable Displacement Engine; SAE Technical Paper; SAE International: Warrendale, PA, USA, 1983. [CrossRef]

21. Wilcutts, M.; Switkes, J.; Shost, M.; Tripathi, A. Design and benefits of dynamic skip fire strategies for cylinder deactivated engines. SAE Int. J. 2013, 6, 278-288. [CrossRef]

22. Stabinsky, M.; Albertson, W.; Tuttle, J.; Kehr, D.; Westbook, J.; Karbstein, H.; Kuhl, M. Active Fuel Management ${ }^{\mathrm{TM}}$ Technology: Hardware Development on a 2007 GM 3.9L V-6 OHV SI Engine; SAE Technical Paper; SAE International: Warrendale, PA, USA, 2007. [CrossRef]

23. Mercedes-AMG Brings Cylinder Deactivation to 5.5L V8; 30\% Reduction in Fuel Consumption. 2011. Available online: http://www.greencarcongress.com/2011/07/m152-20110721.html (accessed on 3 October 2018).

24. Falkowski, A.; McElwee, M.; Bonne, M. Design and Development of the DaimlerChrysler 5.7L HEMI ${ }^{\circledR}$ Engine Multi-Displacement Cylinder Deactivation System; SAE Technical Paper; SAE International: Warrendale, PA, USA, 2004. [CrossRef] 
25. Eisazadeh-Far, K.; Younkins, M. Fuel Economy Gains through Dynamic-Skip-Fire in Spark Ignition Engines; SAE Technical Paper; SAE International: Warrendale, PA, USA, 2016. [CrossRef]

26. Muhamad Said, M.F.; Abdul Aziz, A.A.; Abdul Latiff, Z.A.; Mahmoudzadeh Andwari, A.; Nizam, S. Investigation of Cylinder Deactivation (CDA) Strategies on Part Load Conditions; SAE Technical Paper; SAE International: Warrendale, PA, USA, 2014. [CrossRef] 